\title{
Virtual Brand Community Expectancy of Growth Moderates the Relationship between Community Identification and Community Participation
}

\author{
Hongquan Chen, Wei Gao* \\ Business School \\ Sichuan Agricultural School \\ Chengdu, China \\ gaow956@163.com
}

\author{
Shuhua Zhang \\ Tourism College \\ Sichuan Agricultural School \\ Chengdu, China
}

\author{
Yujin Xu, Yuxuan Liu \\ Business School \\ Sichuan Agricultural School \\ Chengdu, China
}

\begin{abstract}
In the process of studying the impact of community identification on community participation in the virtual brand community, this paper adopted structural equation model of latent interactions without using the mean structure to explore the moderating role of expectancy of growth (hereafter, “EG" ). The results show that the community identification of virtual brand community members directly affects community participation; EG moderates the relationship between community identification and community participation: Community members have high EG, the positive impact of community identification on community participation is significantly enhanced; on the contrary, the positive impact of community identification on community participation is significantly weakened. These findings will help to understand the important role of the EG in the virtual brand community, and also provide new management perspective for e-commerce managers to increase customer participation in their communities.
\end{abstract}

Keywords-Expectancy of Growth (EG); Community Identification; Community Participation; Virtual Brand Community; Without Mean Structure

\section{INTRODUCTION}

Virtual brand community is put forward on the basis of virtual community and brand community. It, through network connection and taking a single brand as the core, refers to a set of interrelationships formed by attracting members, information, technology and other elements [1]. With the rise of social media, virtual brand community has become the main platform for enterprises to interact with customers. Moreover, the virtual brand community is transforming the traditional binary relationship between enterprises and customers into a multiple interactive network relationship among enterprises, customers, potential customers, etc. [2], and gradually becoming the mainstream platform for co-creating experience and value.
In order to adapt to the rapid development of social media and establish a long-term relationship with customers to gain competitive advantage, many mobile phone brands, such as Xiaomi and Huawei, have taken the initiative to establish their own virtual brand community [3]. managers who desire to manage these communities effectively is still facing severe challenges: there are a considerable number of "divers" in the virtual community, and they will not actively interact with the virtual brand community and other members effectively[4]; In addition, generally, the constraints of virtual communities on customers are weak, and the heterogeneity of customers is stronger than that of traditional communities [5], so that customers will leave the community forever once they find themselves unsuited to the virtual community or do not feel the value of the community $[4,6]$.

How to effectively make the community "divers" into "contributors" has become an urgent marketing problem to be solved by the business community. Reviewing the relevant literature on community participation, our researchers study on physical communities more, but relatively less on virtual brand community; scholars pay more attention to customers' current psychological evaluation, such as perceived fairness, satisfaction and so on, but less to the future. In view of this, based on the "psycho-behavioral" paradigm, this paper analyzes the impact of community identification on community participation, and puts EG (i.e., anticipation of increasing numbers of medals), a future-based psychological variable, into this relationship to test its status and role. The contribution of the study is embodied in three aspects. First, it further demonstrates the relationship between community identification and community participation. Secondly, it tests the moderating effect of EG focusing on member's future psychological evaluation, which develops the theory of community participation and arouses more scholars' attention to the moderating effect of latent variables. Third, it provides e- 
commerce managers new management perspective to increase customer participation in their communities.

\section{THEORY AND MODEL}

The theory of expectation holds that individuals are always eager to satisfy certain needs and try to achieve certain goals. This goal is expressed as an expectation before it is achieved, when the goal in turn generates an exciting force on the individual, affecting human behavior [7]. In the virtual brand community, customers are not always easy to achieve their goals, when their specific goals have not been achieved, they will show their EG, which in turn will affect the behavior of community members as an incentive power. Because of the difference of individuals' will, emotion and experience, their EG is strong or weak. So, when the goal is to encourage the individual in turn, the different members will have different degrees of behavior performance. That is to say, the relationship between community identification and community participation, based on the "attitude-behavior" model, will be greatly influenced by EG, which is manifested as a moderating effect. Based on this, we construct the conceptual model shown in Fig.1. Now we make the following assumptions:

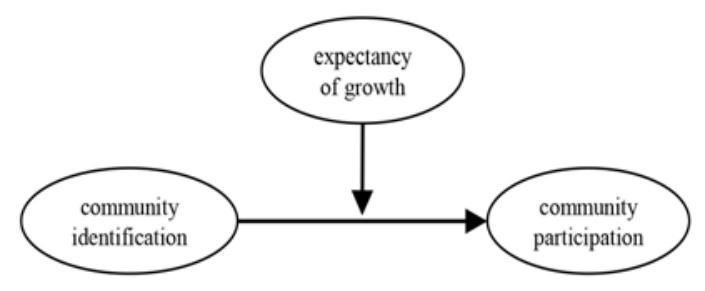

Fig. 1. Conceptual model.

H1. Virtual brand community members' community identification positively affects community participation.

H2. EG plays a moderating role in the relationship between community identification and community participation in the virtual brand community.

H2a. Community members have high EG, the positive impact of community identification on community participation is significantly enhanced.

H2b. Community members have low EG, the positive impact of community identification on community participation is significantly weakened.

\section{METHODS}

\section{A. Instrument Development}

As shown in Table I, all constructs, based on the classic Likert 5-point scale, were measured with multiple item-scales. The scale for measurement EG is developed based on the study of Gen-Yih Liao \& Ching-I Teng [8]. The measurement of community identification and community participation is based on the study of Algesheimer et al. [9].
TABLE I. DEFINITION OF VARIABLES AND ITEMS

\begin{tabular}{|c|c|c|}
\hline Construct & Definition & Item \\
\hline \multirow{4}{*}{$\begin{array}{l}\text { Community } \\
\text { Identificatio } \\
\mathrm{n}\end{array}$} & \multirow{4}{*}{$\begin{array}{l}\text { It refers to the degree } \\
\text { to which members of a } \\
\text { virtual brand } \\
\text { community perceive } \\
\text { their conformity with } \\
\text { the community group, } \\
\text { which is reflected } \\
\text { through three } \\
\text { dimensions: cognition, } \\
\text { emotion and } \\
\text { evaluation. }\end{array}$} & $\begin{array}{l}\text { CI1-I am a member of the } \\
\text { Xiaomi community. }\end{array}$ \\
\hline & & $\begin{array}{l}\text { CI2-The success of the } \\
\text { Xiaomi community is also my } \\
\text { success. }\end{array}$ \\
\hline & & $\begin{array}{l}\text { CI3-I am very concerned } \\
\text { about other people's views on } \\
\text { the Xiaomi community. }\end{array}$ \\
\hline & & $\begin{array}{l}\text { CI4-The identity of the } \\
\text { members of the Xiaomi } \\
\text { community is not important } \\
\text { to me(R). }\end{array}$ \\
\hline \multirow{4}{*}{$\begin{array}{l}\text { Community } \\
\text { Participatio } \\
\mathrm{n}\end{array}$} & \multirow{4}{*}{$\begin{array}{l}\text { The willingness of } \\
\text { members in a virtual } \\
\text { brand community to } \\
\text { actively initiate topics, } \\
\text { discuss with other } \\
\text { members, participate } \\
\text { in community } \\
\text { activities, etc. }\end{array}$} & $\begin{array}{l}\text { CP1-I often participate in } \\
\text { discussions initiated by } \\
\text { members of the Xiaomi } \\
\text { community. }\end{array}$ \\
\hline & & $\begin{array}{l}\text { CP2-I often participate in the } \\
\text { topic and activities initiated } \\
\text { by the official community of } \\
\text { Xiaomi community. }\end{array}$ \\
\hline & & $\begin{array}{l}\text { CP3-I want to maintain my } \\
\text { relationship with the Xiaomi } \\
\text { community. }\end{array}$ \\
\hline & & $\begin{array}{l}\text { CP4-I will continue to } \\
\text { participate in the Xiaomi } \\
\text { community. }\end{array}$ \\
\hline \multirow{3}{*}{ EG } & \multirow{3}{*}{$\begin{array}{l}\text { It refers to a kind of } \\
\text { positive psychological } \\
\text { tension that members } \\
\text { of virtual brand } \\
\text { community are expect } \\
\text { to obtain medals so } \\
\text { that they can be an } \\
\text { expert in collecting } \\
\text { medals. }\end{array}$} & $\begin{array}{l}\text { EG1-I want to have many } \\
\text { medals } \\
\text { community. }\end{array}$ \\
\hline & & $\begin{array}{l}\text { EG2-I want to have some } \\
\text { precious medals of Xiaomi } \\
\text { community. }\end{array}$ \\
\hline & & $\begin{array}{l}\text { EG3-I want to be an expert in } \\
\text { collecting medals in Xiaomi } \\
\text { community. }\end{array}$ \\
\hline
\end{tabular}

\section{B. Data Collection}

In the relatively mature virtual brand community, the virtual community provides a rich source of value attraction, and members face more challenges of differentiation. Moreover, the larger the community size, the greater the heterogeneity among members [5], which is more likely to form varying degrees of $E G$, resulting in a number of expectation-related actions, such as members to obtain product trial qualifications and strive to upgrade their community level. Therefore, this paper chooses Xiaomi community as the research background, which attracts the attention both of academia and business community for its successful community marketing.

Through convenient sampling, 407 questionnaires were collected. Processing the sample data, such as deleting the same IP, no logical samples, 320 valid questionnaires were finally obtained. The effective recovery rate of the questionnaires was 78.6\%. Among them, 203 males accounted for $63.4 \%$; 270 members aged 20-39 accounted for $84.5 \%$, which accounted for the age characteristics of the virtual community population; 275 members with bachelor's degree or above accounted for $85.8 \%$, which accorded with the characteristics that the virtual community population had a higher level of knowledge; 205 members who had joined the community for more than one year. Accounting for $64.2 \%$, the 
respondents were more familiar with the situation of the community.

\section{ANALYSIS AND RESULTS}

\section{A. Reliability and Validity}

Because the scale in this study, combined with the situation of this study to adjust properly, is developed by other scholars, so before the reliability and validity of the data analysis, the author used principal component analysis to analyze the data structure. The KMO value is 0.877, and the Bartlett sphere test is significant, indicating that the data can be analyzed by principal component analysis. Through SPSS21.0 software, this paper adopts the orthogonal rotation variance maximization method to extract the factor based on the eigenvalue greater than 1 , and finally obtains three principal components. The cumulative interpretation variance is $79.87 \%$, which is larger than $50 \%$.

TABLE II. CONFIRMATORY FACTOR ANALYSIS RESULTS

\begin{tabular}{|c|c|c|c|c|c|c|}
\hline Construct & Item & $\lambda^{\mathrm{a}}$ & $\mathbf{P}^{\mathbf{b}}$ & $\alpha$ & CR & AVE \\
\hline \multirow{4}{*}{$\begin{array}{l}\text { Community } \\
\text { Identificatio } \\
\mathrm{n}\end{array}$} & CI1 & 0.828 & $* * *$ & \multirow{4}{*}{0.920} & \multirow{4}{*}{0.920} & \multirow{4}{*}{0.743} \\
\hline & $\mathrm{CI} 2$ & 0.887 & $* * *$ & & & \\
\hline & $\mathrm{CI} 3$ & 0.910 & $* * *$ & & & \\
\hline & CI4 & 0.819 & $* * *$ & & & \\
\hline \multirow{4}{*}{$\begin{array}{l}\text { Community } \\
\text { Participation }\end{array}$} & CP1 & 0.772 & $* * *$ & \multirow{4}{*}{0.880} & \multirow{4}{*}{0.882} & \multirow{4}{*}{0.652} \\
\hline & $\mathrm{CP} 2$ & 0.819 & $* * *$ & & & \\
\hline & $\mathrm{CP} 3$ & 0.874 & $* * *$ & & & \\
\hline & $\mathrm{CP} 4$ & 0.758 & $* * *$ & & & \\
\hline \multirow{3}{*}{ EG } & EG1 & 0.910 & $* * *$ & \multirow{3}{*}{0.915} & \multirow{3}{*}{0.917} & \multirow{3}{*}{0.787} \\
\hline & EG2 & 0.920 & $* * *$ & & & \\
\hline & EG3 & 0.829 & $* * *$ & & & \\
\hline
\end{tabular}

b. All standard factor loading is significant at $\mathrm{P}<0.001$.

The three indexes of reliability test were Cronbach's alpha, Composite Reliability (CR) and Average Variance Extracted (AVE). The general criteria were Cronbach's alpha $>0.7, \mathrm{CR}>$ 0.7 and AVE $>0.5$. The results of the reliability and validity test of the measurement model in this paper are as shown in Table II. The CR values of Cronbach's alpha and combination reliability are above 0.88 and the minimum value of AVE is above 0.6 , far exceeding the above criteria, indicating that the scale has good internal consistency.

TABLE III. RELATION COEFFICIENT MATRIX, AVE AND COMMON VARIANCE $^{\mathrm{a}}$

\begin{tabular}{|l|l|l|l|}
\hline & $\begin{array}{c}\text { Community } \\
\text { Identification }\end{array}$ & $\begin{array}{c}\text { Community } \\
\text { Participation }\end{array}$ & EG \\
\hline $\begin{array}{l}\text { Community } \\
\text { Identification }\end{array}$ & 0.743 & 0.602 & 0.483 \\
\hline $\begin{array}{l}\text { Community } \\
\text { Participation }\end{array}$ & 0.377 & 0.652 & 0.456 \\
\hline EG & 0.284 & 0.197 & 0.787 \\
\hline
\end{tabular}

a. The diagonal values in the table are average variance extracted (AVE), the lower left diagonal is the correlation coefficient matrix, and the upper right diagonal is the common variance of each latent variable and other latent variables $\left(\Phi^{2}\right)$.
The validity of aggregation was judged by three factors: factor loading, CR and AVE. CR is also greater than 0.7, and AVE is greater than 0.5 . For factor loading, it is usually required to be greater than 0.5 . According to the results of Table II, these criteria are satisfied, which shows that the measurement model has good aggregation validity. In addition, the variances interpreted by other latent variables are greater than the common variances of the latent variables and other latent variables, indicating that the data have better discriminatory effectiveness, as shown in Table III.

\section{B. Structural Equation Model Analysis}

Using AMOS 21 software, the maximum likelihood estimation method is used to test the conceptual model proposed in this paper. The results of data analysis are shown in Fig. 2, in which the value of $\chi^{2}$ df is 2.644 (less than 3); CFI is 0.974 ; RMSEA is 0.072 , less than 0.08 , showing that the model has a good fitness. The estimated results of the parameters to be estimated are shown in Fig. 2, the hypothesis $\mathrm{H} 1$ is supported. However, whether EG play a moderating role in the relationship between community identification and community participation remains to be further tested.

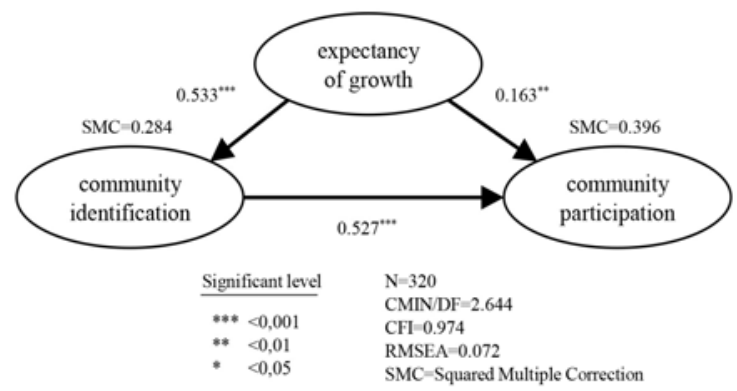

Fig. 2. Structural model results.

\section{Moderating Effect Analysis and Examination}

A popular test for moderating effects is the single product index proposed by Ping in 1995 [10], but Moulder and Algina [11] suggest that the two-step estimates are less accurate. With the development of the latent variable adjustment effect test theory, some scholars reviewed the latent variable interaction modeling methods at home and abroad, and proposed a new unconstrained method without mean structure [12]. This method is simple and accurate, and is welcomed by many ordinary application workers. Therefore, this paper uses this unconstrained method to test the moderating effect of EG.

According to the unconstrained method, the CI 1 with the lowest factor loading is removed firstly, and the indicators of each concept are all centralized. Then, according to the principle of "big matching, small matching", these centralized indicators are paired and multiplied to get new MO1, MO2 and MO3 that are used as indicators to reflect the moderator. The structural equation model is shown in Fig. 3. The analysis results show that the value of $\chi 2 / \mathrm{df}$ is 1.813 (less than 3 ), CFI is 0.982; RMSEA is 0.050 , less than 0.06 , which is an ideal value, so the model fits well. In addition, the path coefficients in the model are significant in different degrees. The standardized estimates of the path coefficients from adjustment variables to 
community participation are 0.151 ( $\mathrm{T}$ is $2.924>1.96, \mathrm{P}$ is $0.003<0.05$ ), which is significant. The rest are shown in Fig. 3. Therefore, H2 is supported.

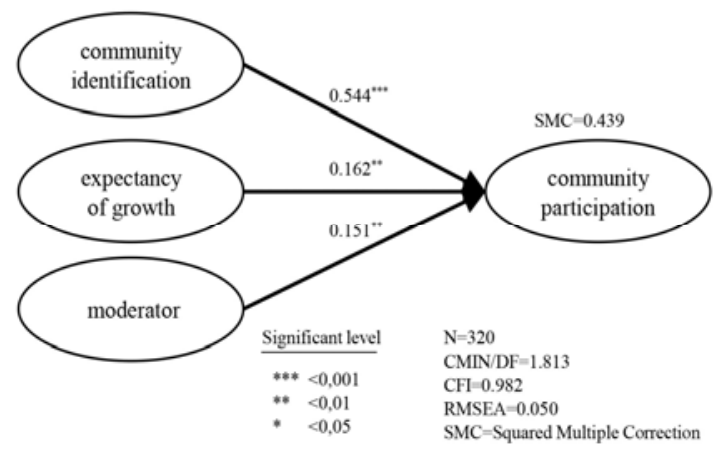

Fig. 3. Moderating effect test.

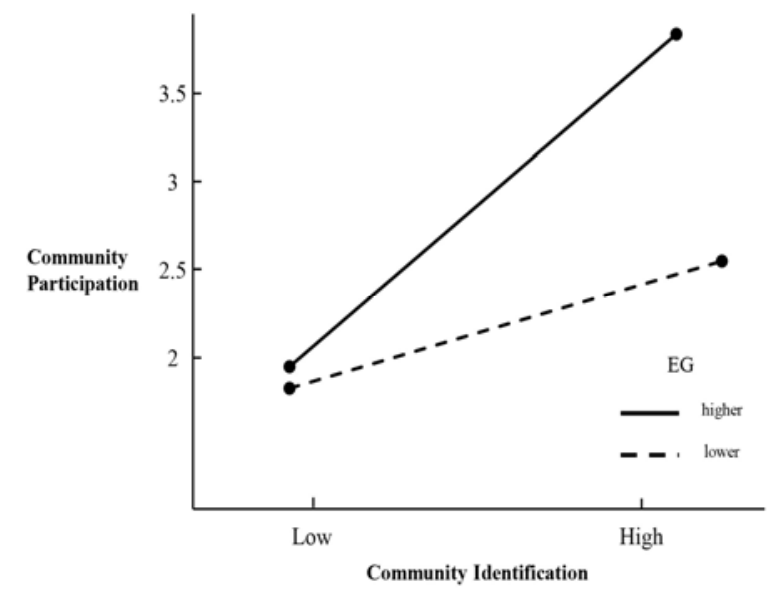

Fig. 4. Moderator effect diagram.

In order to observe the moderate effect of EG more clearly, according to Aiken and West [13], this paper uses SPSS21.0 to make a moderate effect map. Firstly, two standard values of 4.33 and 5.67 are identified according to the mean of EG, and the middle part is removed. Thus, two levels of EG, high and low, can be obtained. Then, the influence of the interaction between two levels of EG and community identification on community participation can be explored by linear regression. The result is shown in Fig. 4. When community members have higher EG, the positive impact of community identification of virtual brand community members on community participation will be significantly enhanced; when community members have lower EG, the positive impact of community identification on community participation will be significantly weakened. Thus $\mathrm{H} 2 \mathrm{a}$ and $\mathrm{H} 2 \mathrm{~b}$ in this paper are supported.

\section{CONCLUSION}

In the virtual brand community, community identification will positively affect community participation. In the research situation of virtual brand community, the moderating effect of
EG is tested in the relationship between community identification and community participation. Specifically, community members have high EG, the positive impact of community identification of virtual brand community members on community participation is significantly enhanced; on the contrary, it is significantly weakened.

EG proposed in this paper involves the evaluation of the future, which are significantly different from previous scholars' concerns about commitment, trust, perceived fairness and so on, which may raise attention from more scholars. What's more, this study shows that there are significant differences in community participation among members of virtual brand community with different growth expectations. Operators in practice, on the basis of trying to enhance the community identity of their members, may affect their level of community participation by influencing their EG, which may be another effective way. The possible way is to change the way and how difficult it is to obtain an meaningful medal.

\section{ACKNOWLEDGMENT}

I would like to express my gratitude to all those who helped me during the writing of this paper.

\section{REFERENCES}

[1] X.Y. Ma, Y.L. Wang, B. Wang, and S. Yang, "A research on the perception, attitudes and behaviors of virtual brand community members," J. Management Review(In Chinese), vol. 29(7), pp. 70-81, 2017.

[2] W. Wei, M. Li, and Z.W. Huang, "Customer engagement behaviors and hotel responses," J. International Journal of Hospitality Management, vol. 33(3), pp. 316-330, July 2013.

[3] K.Y. Goh, C.S. Heng, and Z. Lin, "Social media brand community and consumer behavior: quantifying the relative impact of user- and marketer-generated content," J. Information Systems Research, vol. 24(1), pp. 88-107, 2013.

[4] Z. Zhou, J. P. Wu, Q. Zhang, and $\mathrm{S} \mathrm{Xu,} \mathrm{"Transforming} \mathrm{visitors} \mathrm{into}$ members in online brand communities: evidence from China," J. Journal of Business Research, vol. 66(12), pp. 2438-2443, 2013.

[5] J.Y. Liao, M.X. Huang, and J. Peng, "Investigating the strategies of members socialization in virtual brand communities and its impacts," J. Nankai Business Review(In Chinese), vol. 19(5), pp. 171-181, 2016.

[6] P.J. Bateman, P.H. Gray, and B.S. Butler, "The impact of community commitment on participation in online communities," Information Systems Research, vol. 21(2), pp. 841-854, 2010.

[7] V.H. Vroom, "Work and motivation," J. Industrial Organization Theory \& Practice, vol. 35(2), pp. 2-33, 1964.

[8] G.Y. Liao and C. Teng, "You can make it: expectancy for growth increases online gamer loyalty," J. International Journal of Electronic Commerce, vol. 21(3), pp. 398-423, 2017.

[9] R. Algesheimer, U.M. Dholakia, and A. Herrmann, "The social influence of brand community: evidence from european car clubs," J. Journal of Marketing, vol. 69(3), pp. 19-34, 2005.

[10] R.A. Ping, "A parsimonious estimating technique for interaction and quadratic latent variables," J. Journal of Marketing Research, vol. 32(3), pp. 336-347, 1995.

[11] C.M. Bradley and J. Algina, "Comparison of methods for estimating and testing latent variable interactions," J. Structural Equation Modeling A Multidisciplinary Journal, vol. 9(1), pp. 1-19, 2002.

[12] Y. Wu, Z.L. Wen, and G.Q. Lin, "Structural equation modeling of latent interactions without using the mean structure," J. Acta Psychologica Sinica(In Chinese), vol. 41(12), pp. 1252-1259, 2009.

[13] L.S. Aiken and S.G. West, Multiple regression: Testing and interpreting interactions. Thousand Oaks, CA: Sage Publications, 1991. 